Egyptian

Orthodontic Journal

\title{
EVALUATION OF THE EFFECTS OF THE PENDULUM APPLIANCE IN INTRAORAL MOLAR DISTALIZATION
}

\author{
HÜLYA KILIÇOĞLU*, DDS, PHD; NIL CURA**, DDS, PHD
}

\section{ABSTRACT}

The purpose of this clinical study was to determine dental and skeletal effects of non-compliance pendulum appliance (PA) in upper molar distalization.

The material consisted of 11 Class II patients ( 6 girls, 5 6oys), mean age $14.8 \pm 1.8$ years, with moderate space deficiency in the upper arch; treated with the $\mathcal{P A}$ for bilateral distalization of the upper first molars. The $\mathbb{P A}$ was worn till the super Class $I$ relationship was obtained. The mean treatment duration was 5.90 months ( $S \mathcal{D}=1.87$ months). Lateral cephalometric head films were taken before and at the end of molar distalization; and 22 linear and angular measurements were done to determine skeletal and dental changes. The amount of horizontal movement of molar and incisor teeth was evaluated from superimposition of tracings on the PTV plane; whereas the vertical movement was evaluated from superimposition on the palatal plane. Angular changes were analyzed in relation to $S \mathcal{N}$ plane. Non-parametric Wilcoxon test was used to assess significant changes.

Significant changes were as follows: Upper first and second molars were moved distally (mean $=2.77$ and $2.10 \mathrm{~mm}$, respectively) with a mean distal tipping of $5.77^{\circ}$ and $7.50^{\circ}$. The

From the Department of Orthodontics, Faculty of Dentistry, University of Istanbul

* Associate Professor

** Professor 
Egyptian

Orthodontic Journal

mean anterior movement of the upper incisor was $1.91 \mathrm{~mm}$ without tipping. As, nearly same amount of anterior movement was seen in lower molar $(2.00 \mathrm{~mm})$ and incisor $(1.17 \mathrm{~mm})$ due to normal growth, no significant change was observed in overjet. Significant skeletal change was observed only in the anterior lower face height with increasing of a $0.81 \mathrm{~mm}$.

The results of this study showed that $\mathcal{P A}$ is an effective appliance in molar distalization with an advantage of independence on patient compliance. In addition; side effects, such as significant distal tipping of the molars, need to be taken into consideration in treatment planning.

\section{INTRODUCTION}

One of the possible treatment procedures for patients with Class II malocclusion involves the distalization of the upper first molars. Extraoral traction $^{1-3}$ has traditionally been used to achieve the distal movement of upper molars. Concerns of the patients about wearing an external device have led the development of intraoral alternatives to headgear appliances. ACCO (an acronym for acrylic-cervical-occipital) appliance ${ }^{4-6}$, Wilson bimetric distalizing arches $^{7}$, combination of sliding jigs and Class II intermaxillary elastics ${ }^{8}$ were recommended; however it has been concluded that all these procedures have the major disadvantage of reliance on patient cooperation.

In recent years, with the aid of the evolution in orthodontic materials, new intra-arch procedures were introduced to move the upper molars distally without the need for patient compliance. Non-compliance appliances ${ }^{9-16}$ featuring magnets, NiTi coils and NiTi wires were used in combination with a Nance anchorage appliance and found to be effective in molar distalization. Studies ${ }^{11-13}$, however have demonstrated that complaints of discomfort from the bulk of the magnets and the necessity of the re-activation of the appliance in a short time period because of a quick drop in initial force levels as the inter-magnet distance increased were evident in intra-arch appliances with magnets. In addition, Bondemark and Kurol ${ }^{13}$ concluded that super-elastic coils were more efficient than magnets. NiTi coils ${ }^{17}$ and super-elastic NiTi archwires ${ }^{18}$ may be seen to be advantageous as they apply constantly acting forces on molars, thereby enhancing the rate of molar movement ${ }^{6,16}$. 
During treatment with any of these appliances, overcorrection of the molar relationship is recommended for two reasons. First, to compensate for the anchorage loss that invariably occurs with subsequent retraction of the anterior teeth. Second, as the molars tip during distal movement, overcorrection is necessary to maintain the Class I relationship as subsequent forward movement of the crown of the molars is likely during the uprighting of molars.

In 1992, Hilgers ${ }^{19}$ described a non-compliance appliance for maxillary molar distalization called the "pendulum". As is the case with similar previously mentioned intra-arch procedures, the pendulum appliance has a large Nance anchorage button along with .032" TMA springs that deliver a light, continuous force in a swinging arc movement ("pendulum") to the upper first molars. The pendulum appliance can also be constructed with an expansion screw ("pendex") for simultaneous palatal expansion. The anchorage support for the appliance was obtained through occlusally bonded rests or retaining wires soldered to bands on first deciduous molars or first premolars. The TMA springs were activated $60^{\circ}$ to produce a force of $230 \mathrm{gm}$ per side. To maintain the new molar position overcorrection as well as post-treatment retention is recommended. After removal of the pendulum appliance (PA), one of the following procedures can be used to stabilize the new molar position: the appliance including smaller Nance button, upper utility arch, continuous upper archwire with omega loops mesial to the upper first molar tubes or headgear appliance for a short time.

Only a few studies have been published ${ }^{19-24}$ related with the effects of the pendulum appliance (PA). Thus, the purpose of this study was to determine dental and skeletal effects of non-compliance pendulum appliance (PA) in upper molar distalization and compare these results with previous findings.

\section{Materials and Methods}

Consecutively treated eleven patients (6 girls, 5 boys) who met the following criteria were selected from patients referred for orthodontic treatment:

1.Bilateral Class II dental relationship

2.moderate arch length discrepancy in the maxillary arch

3.non-extraction treatment plan including bilateral upper molar distalization as the first phase of treatment.

The mean age was 14.8 years ( $\mathrm{SD}=1.8$ years; range $12.1-18.1$ years). Gender differences were not considered due to the short duration of the treatment with pendulum appliance. Maxillary second molars were in occlusion 
bilaterally in seven patients; erupted unilaterally in three patients and not erupted in one patient. All patients had unerupted maxillary third molars as detected on panoramic radiographs.

\section{Appliance design and activation}

All patients received a pendulum appliance similar to the type described by Hilgers ${ }^{19}$. It consisted of a large Nance acrylic button constructed with supporting arms soldered to banded maxillary first premolars. Right and left 0.032" TMA wire springs, embedded in the Nance button, were inserted into lingual sheaths $(0.036 ")$ on the bands attached to the maxillary first molars (Fig.1). In all patients a one-time initial activation of $60^{\circ}-70^{\circ}$ of the spring was delivered and the adjustment loops were not activated during treatment. The TMA springs exerted $230 \mathrm{~g}$ of force, as the springs were activated $60^{\circ}{ }^{19}$. The patients were monitored at monthly intervals and the treatment with the appliance was ended when the super class I molar relationship was obtained. The mean treatment duration was 5.9 months $(\mathrm{SD}=1.9$ months; range $4.0-8.8$ months). After the removal of the appliance, headgear was placed on first molars to prevent relapse. The premolars and canines were allowed to drift distally before the insertion of full fixed appliance.

\section{Cephalometric Analysis}

Cephalometric radiographs were obtained on all patients prior to treatment and on the day the appliance was removed. All radiographs were traced by one (NC) investigator. In instances of double images an averaged tracing was made. Centroid points (midpoint between the greatest mesial and distal convexity of the crown) were constructed for the crowns of all evaluated molar teeth (Fig.3).

Cephalometric measurements used in this study are showing in Figs 2-4. Horizontal dental changes as well as changes in sagittal jaw relationship were determined from superimposition of the cephalometric tracings on the pterygiod vertical plane (PTV) (Fig.2 and 4) and vertical dental movements were determined from superimposition on the palatal plane (PP $)^{20}$ (Fig.4).

\section{Statistical Analysis}

Descriptive statistics [means, standard deviations, minimum (min) and maximum $(\max )]$ were calculated for each measurement. The changes obtained during treatment were evaluated by using non-parametric Wilcoxon test. 


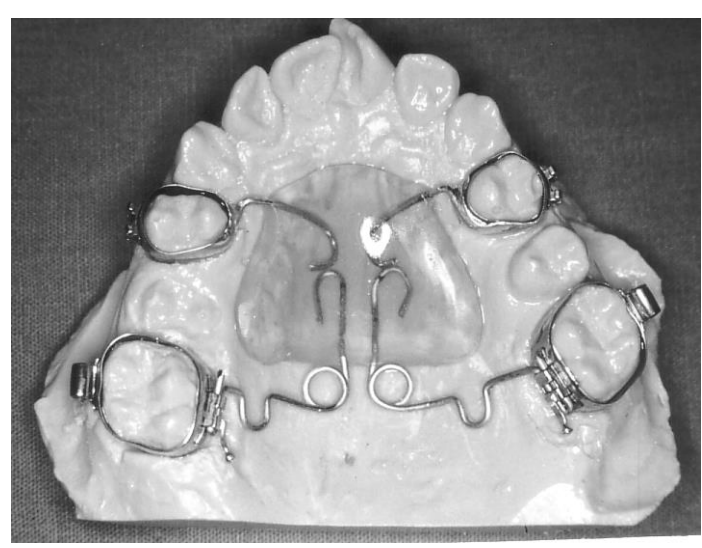

Figure 1. Pendulum appliance used in this study.

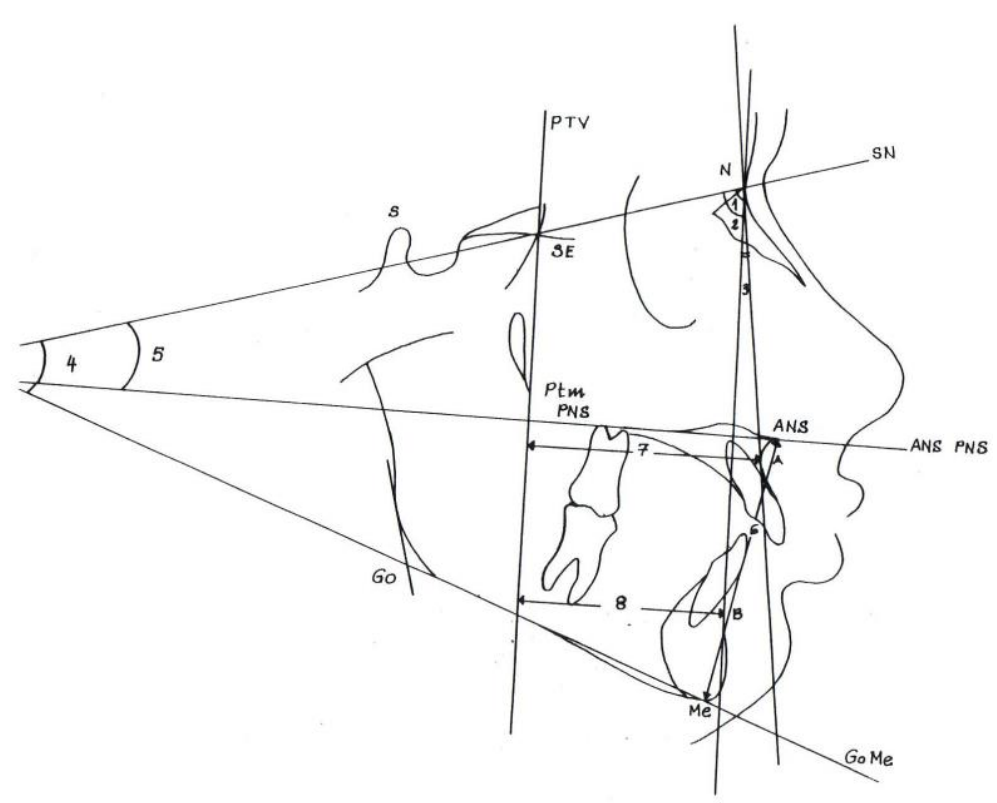

Figure 2. Cephalometric skeletal measurements used in study: Angular measurements: (1) SNA, (2) SNB, (3) ANB, (4) SN-GoMe, (5) SN-ANSPNS. Linear measurements: (6) ANS-Me, (7) PTV-A, (8) PTV-B. 


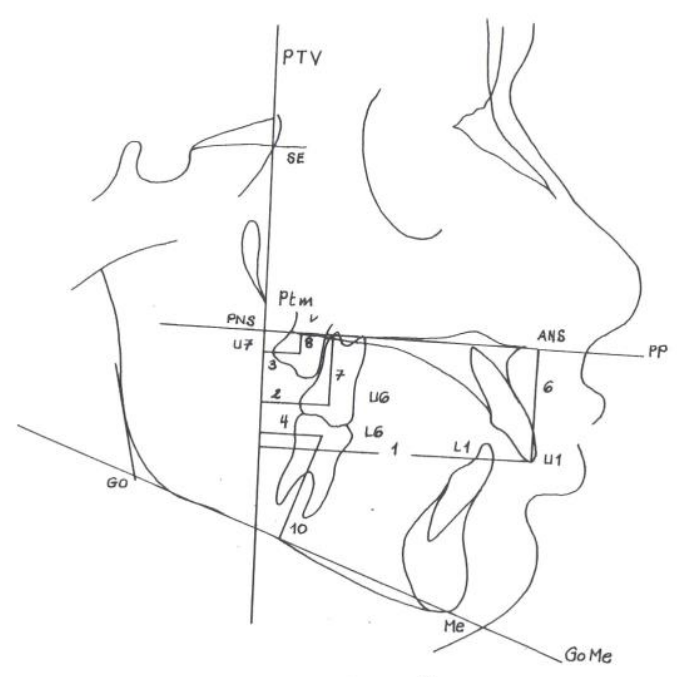

Figure 3. Cephalometric dental linear measurements used in study: Horizontal measurements (1) PTV-U1, (2) PTV-U6, (3) PTV-U7, (4) PTV-L6, (5) Overjet [(PTV-U1)(PTV-L1)]. Vertical measurements: (6) PP-U1, (7) PP-U6, (8) PP-U7, (9) Overbite [(PP-U1)-(PP-L1)], (10) GoMe-L6.

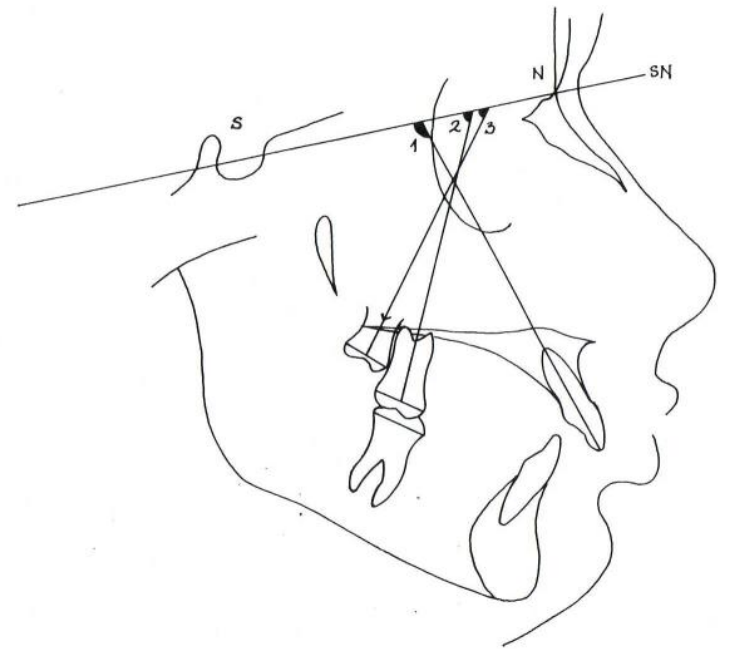

Figure 4. Cephalometric dental angular measurements used in study: (1) SN-U1, (2) SNU6, (3) SN-U7. 
Egyptian

Orthodontic Journal

\section{RESULTS}

In all patients the appliance was well tolerated; no irritation and breakage was occurred. A super Class I molar relationship was obtained in all patients during the treatment with pendulum appliance (Fig.5). A spontaneous distal drift of upper premolars was also evident clinically in all patients. Also, the patients had no complaints related with sleeping headgears.

The mean, standard deviation, minimum (min), maximum (max) values of the pre- and post-treatment as well as changes in the measurements are summarized in Tables 1 and 2.

As a result, it appears that the pendulum appliance primarily affected the maxillary dentition. These effects were summarized as follows: the upper first molars were moved posteriorly $(2.77 \pm 1.52 \mathrm{~mm})$ and tipped distally $\left(5.77 \pm 4.87^{\circ}\right)$. Similar changes were observed in upper second molars. They were distalized $2.09 \pm 1.36 \mathrm{~mm}$ and tipped distally $7.50 \pm 6.11^{\circ}$.

A little loss of anchorage was evident as seen in anterior movement of the upper incisors $(1.91 \pm 1.22 \mathrm{~mm})$ without flaring. However, pre-treatment overjet was maintained as a result of anterior movement of mandibular dentition (molars $=2.00 \pm 1.27 \mathrm{~mm}$; incisors $=1.18 \pm 1.47 \mathrm{~mm})$ attributed to anterior movement of the mandible $(1.27 \pm 1.40 \mathrm{~mm})$. These mentioned mandibular changes also helped the correction of class II molar relationship.

No significant vertical change of molars and incisors was observed.

The only significant $(\mathrm{p}<0.05)$ skeletal effect of the pendulum appliance was reflected in the lower anterior facial height (ANS-Me); which increased an average of $0.82 \pm 0.78 \mathrm{~mm}$.

\section{DISCUSSION}

The results of this study show that effects of the pendulum appliance are more pronounced on maxillary dentition, with little effects on skeletal structure.

The results also showed that the pendulum appliance is an effective appliance in distalization of upper molars without patient compliance.

In addition, one-time initial activation of $60^{\circ}-70^{\circ}$ was found to be effective in obtaining super Class I molar relationship. This may be the one important advantage of PA appliance when comparing other distalization mechanics ${ }^{5-7,9-13}$ that need some kind of re-activation. 
Egyptian

Orthodontic Journal

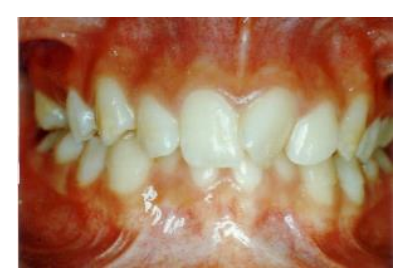

5A

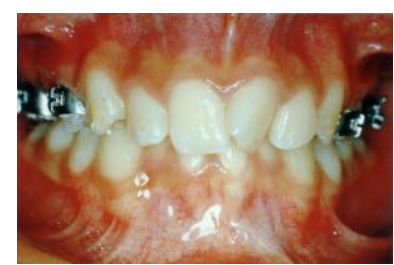

5D

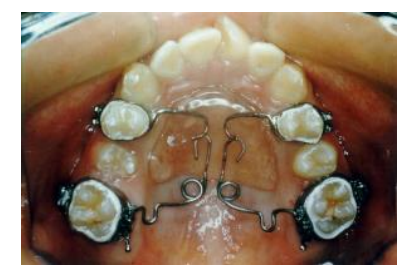

5G

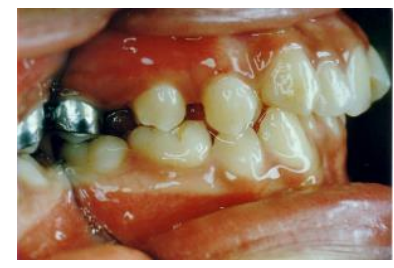

5J

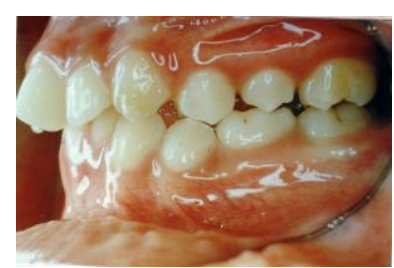

5B

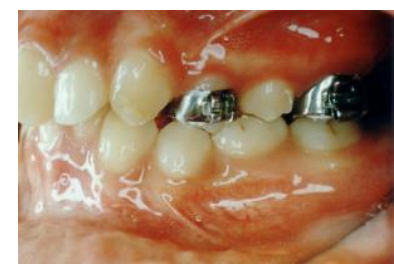

$5 \mathrm{E}$

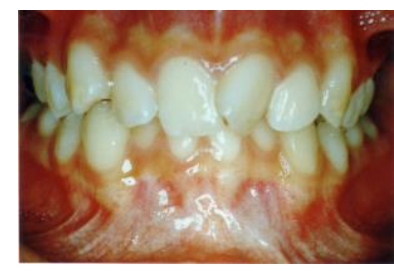

$5 \mathbf{H}$

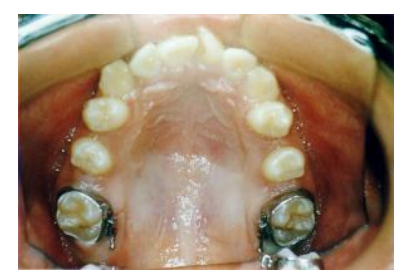

$5 \mathrm{~K}$

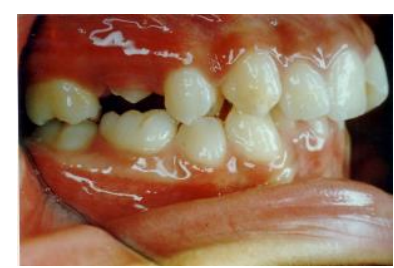

5C

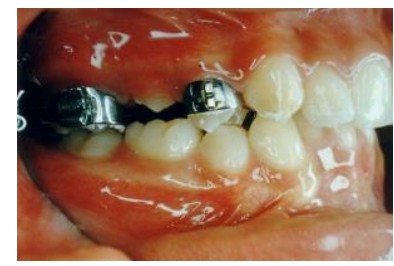

$5 F$

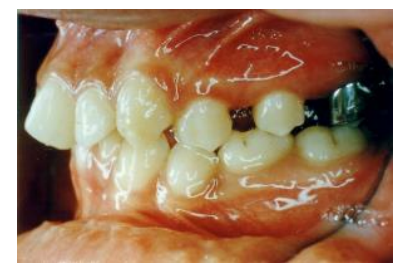

5I

Figure 5. One of the patients before treatment $(\mathrm{A}-\mathrm{C})$, at the beginning of treatment when the appliance was inserted (D-G), at the end of treatment after the appliance removal (H-K). 
When comparing the results of the rate of movement and amount of tipping of upper molars with previous PA studies it was seen that less amount of rate and tipping observed in this study. The maxillary first molar moved posteriorly at a mean rate of $0.55 \mathrm{~mm} /$ month $( \pm 0.29 \mathrm{~mm})$, for a total $2.77 \mathrm{~mm}$ in 5.9 months. In comparison; Ghosh and Nanda ${ }^{20}$ achieved a mean distal movement of $3.37 \mathrm{~mm}$ in 6.2 months, a monthly rate of $0.54 \mathrm{~mm}$, close to our findings. More distalization was reported in three other studies $(21,23,24)$ : Byloff and Darendeliler ${ }^{21}$ found $3.39 \mathrm{~mm}$ of distal molar movement in a period of 16.6 weeks, a monthly rate of $1.02 \mathrm{~mm}$; Joseph and Butchart ${ }^{23}$ reported an average of $5.1 \mathrm{~mm}$ molar distalization, a monthly rate of $1.5 \mathrm{~mm}$ while Bussick and $\mathrm{McNamara}^{24}$ pointed out $5.7 \mathrm{~mm}$ molar distalization, a monthly rate of $0.8 \mathrm{~mm}$.

Gianelly ${ }^{16}$ pointed out that faster movement occurs when molar tipping was evident. Ghosh and $\mathrm{Nanda}^{20}$ also found a significant correlation between the amount of distalization and the amount of first molar tipping $(\mathrm{r}=0.488)$. Similarly, mean distal molar tipping of $5.77^{\circ}$ found in present study was lower than that reported in previous PA studies (Ghosh and Nanda ${ }^{20}$, Byloff and Darendelile ${ }^{21}$ Joseph and Butchart ${ }^{23}$ and Bussick and McNamara ${ }^{24}$ found distal tipping of $8.4^{\circ}, 14.5^{\circ}, 15.7^{\circ}$ and $10.6^{\circ}$; respectively) seems to support this opinion.

One of the factors that related molar distalization is the presence or absence of upper second molars. However, the influence of second molars on the amount and type of distal movement of the upper first molar has been subject of debate. It has been stated ${ }^{16,24}$ that an optimal time to move upper molars distally is the late mixed dentition stage of development, before the eruption of second molars. It has been suggested that after the eruption of second molars, distalization can be more difficult, time-consuming, loss of anchorage ${ }^{9,10,14-16}$ and more extrusion in upper molars with increase in lower facial height is likely ${ }^{24}$. In contrast, recent clinical studies with pendulum appliance ${ }^{20-24}$ and Wilson distalizing $\operatorname{arch}^{25}$ showed that either the amount of distalization of the molars or duration of treatment were not dependent on the presence of erupted second molars. In addition, the amount of tipping of the upper first molars does not correlate with the presence of second upper molars ${ }^{21,24,25}$. In the present study, all patients, except one, had second molars erupted bilaterally or unilaterally and these teeth also showed a mean distal movement of $2.1 \mathrm{~mm}$ with tipping of $7.5^{\circ}$.

Evaluating the activation type of the appliance, similar type of activation were used in our and Ghosh and Nanda' ${ }^{20}$ study that one time activation of $60^{\circ}$ $70^{\circ}$. It produced a $230 \mathrm{~g}$ of force per side ${ }^{19}$. Also, the results of these two studies related with tipping of molars were nearly identical. Differences were observed 
in activation of PA appliance in the other three PA studies, found more distal tipping in molars. Joseph and Butchart ${ }^{23}$ used single activation of $90^{\circ}$ (345 $\mathrm{g}$ of force); Bussick and McNamara ${ }^{24}$ used $60^{\circ}-90^{\circ}$ (230-345g of force) and Byloff and Darendeliler ${ }^{21}$ used activation repeated once or twice of $45^{\circ}$ (170 $\mathrm{g}$ of force). This different type of activation may be resulted in different degree of tipping in molar movements between the PA studies. In addition, distinction in measurement procedures may be the reason of this difference.

Molar tipping during distalization is the most important side effect that needs to be taken into consideration in treatment planning, due to the obvious risk of relapse. Byloff and Darendeliler ${ }^{22}$ and Keleş and Sayınsu ${ }^{26}$ modified the appliance. Byloff and Darendeliler ${ }^{22}$ incorporate an uprighting bend in the pendulum appliance to counteract tipping. They conclude that PA with uprighting bends led to reduce molar tipping, with the exceptions of more anchorage loss of maxillary incisors and increased treatment time. In recently published articles Keleş and Sayınsu ${ }^{26}$ modified TMA springs of the appliance. The springs had two component, distalizing and uprighting section. They conclude that, unlike most of the other molar distalization mechanics, this device, named IBMD (intraoral bodily molar distalizer), achieved bodily distal movement of maxillary molars. However, in that study more anchorage loss was evident as protrusion of $4.7 \mathrm{~mm}$ of maxillary incisors.

Significant anterior movement $(1.91 \mathrm{~mm})$ of the maxillary incisors was observed in present study with no change in angulation. As nearly same amount of anterior movement was seen in mandibular dentition (Table 2) which resulted from normal growth, the change related with upper incisors could not be related with the effects of the appliance. These mentioned mandibular changes also helped overjet to remain unchanged during treatment. Byloff and Darendeliler ${ }^{21}$ also found little incisor anchorage loss. In contrast, Joseph and Butchart ${ }^{23}$ found significant increase in maxillary incisor proclination and overjet; and concluded that there appears to be some correlation to the amount of distalization and the extent of incisor protrusion. As less amount of anchorage loss was evident in studies, which used modify Nance button ${ }^{10,12}$, full coverage of palate has been recommended to reinforce the anchorage unit ${ }^{20}$.

The treatment caused significant increase in lower anterior facial height (ANS-Me). This $0.82 \mathrm{~mm}$ increase was the only vertical parameter showing 
significant changes (Table 2); which results from nonsignificant increase in mandibular plane angle due to the distalization of upper molars. Similar increases in lower anterior facial height were found in previous studies of the pendulum appliance $e^{20,23}$.

Table1. Descriptive statistics for pretreatment and post-treatment cephalometric measurements $(n=11)$.

\begin{tabular}{|c|c|c|c|c|c|c|c|c|}
\hline \multirow[b]{2}{*}{ Measurements } & \multicolumn{4}{|c|}{ Pre-treatment } & \multicolumn{4}{|c|}{ Post-treatment } \\
\hline & Mean & SD & Min. & Max. & Mean & SD & Min. & Max. \\
\hline \multicolumn{9}{|l|}{ Skeletal } \\
\hline SNA & 79.00 & 2.17 & 74.00 & 82.00 & 79.00 & 2.26 & 73.50 & 82.00 \\
\hline SNB & 74.41 & 2.32 & 71.00 & 78.00 & 74.55 & 2.53 & 70.00 & 78.00 \\
\hline ANB & 4.59 & 1.95 & 0.50 & 7.00 & 4.45 & 2.23 & 1.00 & 8.00 \\
\hline SN-GoMe & 32.27 & 7.17 & 20.00 & 42.50 & 32.59 & 7.29 & 20.00 & 42.50 \\
\hline SN - ANSPNS & 13.09 & 2.83 & 7.00 & 16.50 & 12.91 & 2.74 & 7.50 & 16.50 \\
\hline $\mathrm{ANS}-\mathrm{Me}$ & 63.05 & 3.84 & 56.00 & 68.00 & 63.86 & 3.76 & 56.00 & 69.00 \\
\hline PTV - A & 51.27 & 2.66 & 47.00 & 56.00 & 51.77 & 2.65 & 47.00 & 56.00 \\
\hline PTV - B & 48.05 & 3.85 & 42.00 & 54.00 & 49.32 & 3.87 & 45.00 & 56.00 \\
\hline \multicolumn{9}{|c|}{ Dental - angular $\left({ }^{\circ}\right)$} \\
\hline $\mathrm{SN}-\mathrm{U} 1$ & 96.96 & 8.27 & 83.00 & 108.00 & 99.00 & 8.00 & 86.00 & 116.50 \\
\hline $\mathrm{SN}-\mathrm{U} 6$ & 63.96 & 6.73 & 56.00 & 80.00 & 58.18 & 6.17 & 48.00 & 68.00 \\
\hline $\mathrm{SN}-\mathrm{U} 7$ & 56.27 & 5.42 & 48.50 & 66.00 & 48.77 & 5.99 & 41.00 & 61.00 \\
\hline \multicolumn{9}{|c|}{ Dental - linear $(\mathrm{mm})$ - horizontal } \\
\hline PTV - U1 & 56.46 & 3.64 & 51.00 & 63.00 & 58.36 & 3.14 & 54.00 & 63.00 \\
\hline PTV - L1 & 52.09 & 3.62 & 47.00 & 57.00 & 53.27 & 3.41 & 49.00 & 58.00 \\
\hline Overjet & 4.36 & 1.29 & 2.00 & 6.00 & 5.09 & 1.87 & 2.00 & 8.00 \\
\hline PTV - U6 & 22.91 & 2.29 & 19.00 & 26.00 & 20.14 & 2.48 & 16.00 & 24.00 \\
\hline PTV - U7 & 12.09 & 1.56 & 9.00 & 15.00 & 10.00 & 1.87 & 7.00 & 13.00 \\
\hline PTV - L6 & 19.82 & 2.84 & 15.50 & 26.00 & 21.82 & 3.04 & 16.50 & 27.00 \\
\hline \multicolumn{9}{|c|}{ Dental - linear (mm) - vertical } \\
\hline $\mathrm{PP}-\mathrm{U} 1$ & 27.55 & 2.09 & 25.00 & 31.50 & 27.73 & 1.94 & 25.50 & 31.50 \\
\hline $\mathrm{PP}-\mathrm{U} 6$ & 19.32 & 2.63 & 15.00 & 24.00 & 18.91 & 3.19 & 14.00 & 25.50 \\
\hline $\mathrm{PP}-\mathrm{U} 7$ & 14.46 & 5.40 & 3.50 & 22.00 & 13.18 & 5.24 & 3.00 & 22.50 \\
\hline GoMe - L6 & 27.64 & 2.97 & 22.00 & 31.5 & 27.82 & 2.81 & 22.50 & 31.00 \\
\hline Overbite & 4.36 & 2.19 & 1.00 & 8.00 & 4.09 & 2.26 & 1.00 & 8.00 \\
\hline
\end{tabular}


Egyptian

Orthodontic Journal

Table2. Changes in cephalometric measurements during treatment and their significance $(n=11)$.

\begin{tabular}{|c|c|c|c|c|c|}
\hline Measurements & Mean & SD & Min. & Max. & $\mathbf{P}$ \\
\hline \multicolumn{6}{|l|}{ Skeletal } \\
\hline SNA & 0.00 & 0.55 & -1.00 & 1.00 & Ns \\
\hline SNB & 0.14 & 0.90 & -1.00 & 1.50 & Ns \\
\hline ANB & -0.14 & 0.84 & -1.50 & 1.00 & Ns \\
\hline $\mathrm{SN}-\mathrm{GoMe}$ & 0.32 & 1.27 & -1.50 & 3.50 & Ns \\
\hline $\mathrm{SN}-\mathrm{ANSPNS}$ & -0.18 & 1.23 & -3.00 & 1.50 & Ns \\
\hline $\mathrm{ANS}-\mathrm{Me}$ & 0.82 & 0.78 & -1.00 & 2.00 & $*$ \\
\hline PTV - A & 0.50 & 1.07 & -0.50 & 2.50 & Ns \\
\hline $\mathrm{PTV}-\mathrm{B}$ & 1.27 & 1.40 & -0.50 & 3.00 & Ns \\
\hline \multicolumn{6}{|c|}{ Dental-angular $\left({ }^{o}\right)$} \\
\hline $\mathrm{SN}-\mathrm{U} 1$ & 2.05 & 3.66 & -4.00 & 8.50 & Ns \\
\hline $\mathrm{SN}-\mathrm{U} 6$ & -5.77 & 4.87 & -16.50 & 0.50 & $*$ \\
\hline $\mathrm{SN}-\mathrm{U} 7$ & -7.50 & 6.11 & -14.5 & 9.00 & $*$ \\
\hline \multicolumn{6}{|c|}{ Dental-linear $(\mathrm{mm})-$ horizontal } \\
\hline PTV - U1 & 1.91 & 1.22 & 0.00 & 3.00 & $* *$ \\
\hline PTV - L1 & 1.18 & 1.47 & -2.00 & 3.00 & $*$ \\
\hline Overjet & 0.73 & 1.01 & 0.00 & 3.00 & Ns \\
\hline PTV - U6 & -2.77 & 1.52 & -4.50 & -0.50 & $* *$ \\
\hline PTV - U7 & -2.09 & 1.36 & -4.50 & 0.00 & $* *$ \\
\hline PTV - L6 & 2.00 & 1.27 & 0.50 & 4.00 & $* *$ \\
\hline \multicolumn{6}{|c|}{ Dental-linear $(\mathrm{mm})-$ vertical } \\
\hline $\mathrm{PP}-\mathrm{U} 1$ & 0.18 & 1.03 & -1.50 & 2.00 & Ns \\
\hline $\mathrm{PP}-\mathrm{U} 6$ & -0.41 & 1.58 & -2.50 & 2.50 & Ns \\
\hline $\mathrm{PP}-\mathrm{U} 7$ & -1.27 & 1.35 & -3.00 & 0.50 & Ns \\
\hline GoMe - L6 & 0.18 & 0.78 & -1.50 & 1.50 & Ns \\
\hline Overbite & -0.27 & 0.88 & -2.00 & 1.00 & $\mathrm{Ns}$ \\
\hline
\end{tabular}

ns: not significant; $* \mathrm{p}<0.05 ; * * \mathrm{p}<0.01$

\section{CONCLUSION}

The results of this study showed that effects of the pendulum appliance (PA) are exclusively seen in the maxillary dentition, with little effects on skeletal structure. PA is an effective appliance for molar distalization with the advantage of acting independent to patient compliance. Side effects showed, such as significant distal tipping of the molars, needs to be taken into consideration in treatment planning. 
Egyptian

Orthodontic Journal

\section{References}

1. Baumrind S, Korn EL, Isaacson RJ, West EE, Molthen R.Quantitative analysis of the orthodontic and orthopedic effects of maxillary traction. Am J Orthod 1983;84:384-93.

2. Kloehn SJ. Evaluation of cervical traction of the maxilla and maxillary first permanent molar. Angle Orthod 1961;31:91-104.

3. Wieslander L. Early or late cervical traction therapy of Cl II malocclusion in the mixed dentition. Am J Orthod 1975;67:432-9.

4. Cetlin NM, Ten Hoeve A. Nonextraction treatment. J Clin Orthod 1983; 17:396-413.

5. Warren DW. Clinical application of the ACCO appliance. Part I. Am J Orthod Dentofac Orthop 1992;101:101-11.

6. Dietz VS, Gianelly AA. Molar distalization with the acrylic cervical occipital appliance. Sem in Orthod 2000;6(2):91-7.

7. Wilson WL, Wilson RC. Multi-directional 3D functional Class II treatment. J Clin Orthod 1987;21:186-9.

8. Tweed CH. Clinical Orthodontics. Vol. 1. St Louis: CV Mosby, 1966.

9. Gianelly AA, Vaitas AS, Thomas WM, Berger DG. Distalization of molars with repelling magnets. J Clin Orthod 1988;22:40-4.

10. Gianelly AA, Vaitas AS, Thomas WM. The use of magnets to move molars distally. Am J Orthod Dentofac Orthop 1989;96:161-7.

11. Itoh T, Tokuda T, Kiyosue S, Hirose T, Matsumoto M, Chaconas SJ. Molar distalization with repelling magnets. J Clin Orthod 1991;25:611-7.

12. Bondemark L, Kurol J. Distalization of maxillary first and second molars simultaneously with repelling magnets. Eur J Orthod 1992;14:264-72.

13. Bondemark L, Kurol J. Repelling magnets versus superelastic nickel-titanium coils in simultaneous distal movement of maxillary first and second molars. Angle Orthod 1994;64:189-98.

14. Gianelly AA, Bednar J, Dietz VS. Japanese NiTi coils used to move molars distally. Am J Orthod Dentofac Orthop 1991;99:564-6. 
15. Locatelli R, Bednar J, Dietz VS, Gianelly AA. Molar distalization with superelastic NiTi wire. J Clin Orthod 1992;26:277-9.

16. Gianelly AA. Distal movement of maxillary molars. Am J Orthod Dentofac Orthop 1998;114:66-72.

17. Miura $\mathrm{F}$ et al. The super-elastic Japanese NiTi alloy wire for use in orthodontics.PartIII. Studies on the Japanese NiTi allot coil springs. Am J Orthod Dentofac Orthop1988;94:89-96.

18. Miura F et al. The superelastic property of the Japanese NiTi alloy wire for use in orthodontics. Am J Ortod Dentofac Orthop 1986;90:1-10.

19. Hilgers JJ. The pendulum appliance for class II non-compliance therapy. J Clin Orthod 1992;26:706-14.

20. Ghosh J, Nanda RS. Evaluation of an intraoral maxillary molar distalization technique. Am J Orthod Dentofac Orthop 1996;110:639-46.

21. Byloff FK, Darendeliler MA. Distal molar movement using the pendulum appliance. Part 1: Clinical and radiological evaluation. Angle Orthod 1997;67:249-60.

22. Byloff FK, Darendeliler MA, Clar E, Darendeliler A. Distal molar movement using the pendulum appliance. Part 2: The effects of maxillary molar root uprighting bends. Angle Orthod 1997;67:261-270.

23. Joseph AA, Butchart CJ. An evaluation of the pendulum distalization appliance. Semin in Orthod. 2000;6(2):129-35.

24. Bussick TJ, McNamara JA Jr. Dentoalveolar and skeletal changes associated with the pendulum appliance. Am J Orthod Dentofac Orthop 2000;117:333-43.

25. Muse DS, Fillman MJ, Emmerson WJ, Mitchell RD. Molar and incisor changes with Wilson rapid molar distalization. Am J Orthod Dentofac Orthop 1993; 104:556-65.

26. Keleş A, Sayınsu K. A new approach in maxillary molar distalization: Intraoral bodily molar distalizer. Am J Orthod Dentofac Orthop 2000;117:3948. 